Cerebrovasc Dis 2011;31:417

DOI: $10.1159 / 000322951$

\section{Reply to the Letter by K.S. Tan and C.T. Tan: Ischaemic Stroke in Young Asian Women: Incomplete Investigations and Geographical Bias}

\section{Wasay}

Department of Medicine/Neurology, Aga Khan University, Karachi, Pakistan

We are thankful to Tan and Tan for critiquing the article in great detail [1]. We shall address the issues pointwise.

It is true that the majority of patients were recruited from South Asia, but patients were recruited from three out of four regions of Asia, which also justifies the title. This is common practice in medical literature. An international study on cerebral venous thrombosis (ISCVT) recruited more than $80 \%$ of patients from Europe while few were recruited from North America and Asia and none from Africa and Australia, but the study was still titled 'international study' [2]. The study reported by K.S. Tan is a comparison of single-center stroke data from Kuala Lumpur, Malaysia, and Melbourne, Australia. The study population was not representative of either country, but it was still titled 'A comparative study between Malaysia and Australia' [3]. The study under review was not representative of all Asian women with stroke but it is the largest dataset of Asian women with stroke.

Despite the fact that the data of $59 \%$ of the patients were collected by retrospective chart reviews, missing data were not substantial. Many of the participating centers had established stroke registries to authenticate the data retrieved from retrospective reviews.

It is incorrect that $14 \%$ of patients did not get CT or MRI. All enrolled patients had CT scan or MRI, which was part of our inclusion criteria. Most patients with stroke do not need all tests (echocardiogram, carotid Doppler ultrasound and magnetic resonance angiogram) for classification according to the TOAST criteria. Rational stroke workup was done in most of the patients. It was a rational decision as to which tests are required according to the patient's medical history. Patients with cerebral venous thrombosis (CVT, 20\%) did not require arterial stroke workup. Carotid Doppler ultrasound and magnetic resonance angiogram were not done in patients with atrial fibrillation or with confirmed cardioembolic stroke. Reasonable workup was done among these patients to identify large-vessel versus small-vessel disease and cardioembolic stroke. Limited workup was done to identify stroke patients with other determined aetiology. The number of patients with unknown or ill-defined aetiology was high (17\%) due to limited workup in this category.

We read the study by Tan et al. [3] with interest. It enrolled patients up to age 49 years and of both genders ( 28 women). In this study, $11 \%$ women (3 out of 28 ) with stroke had CVT. This number was high as compared to only 1 out of 24 women in Australia. This finding is in agreement with our findings that CVT is high in Asian women as compared to the Caucasian population. There are regional differences in Asian populations related to stroke subtypes, especially with respect to the frequency of CVT. We did not perform a regional analysis in our study but previous reports indicate that the prevalence of CVT is especially high in the South Asian region. A study from India reported that $40 \%$ of stroke incidence in young women were due to CVT [4]

We agree that there is a need for further studies from all parts of Asia with more extensive and uniform work. Future collaborative research in Asian countries may identify areas of intervention to reduce the burden of stroke in Asia.

\section{References}

1 Tan KS, Tan CT: Ischaemic stroke in young Asian women: incomplete investigations and geographical bias. Cerebrovasc Dis 2011;31:416.

2 Ferro JM, Canhao P, Stem J, Bousser MG, Barinagarrementeria F for ISCVT investigators: Prognosis of cerebral vein and dural sinus thrombosis: results of the international study on cerebral vein and dural sinus thrombosis (ISCVT). Stroke 2004;35:664-670.

- 3 Tan KS, Tan CT, Churilov L, Mackay M, Donnan GA: Ischaemic stroke in young adults: a comparative study between Malaysia and Australia. Neurol Asia 2010;15:1-9.

-4 Panagariya A, Maru A: Cerebral venous thrombosis in pregnancy and puerperium - a prospective study. J Assoc Physicians India 1997;45: 857-859.

Mohammad Wasay, FRCP

Department of Medicine/Neurology

Aga Khan University, Stadium Road

Karachi 74800 (Pakistan)

Tel. +92 21493 0051, ext. 4665, Fax +92 214934294

E-Mail mohammad.wasay@aku.edu

\begin{tabular}{ll}
\hline KARGER & (1) 2011 S. Karger AG, Basel \\
Fax +4161306 1234 $34-9770 / 11 / 0314-0417 \$ 38.00 / 0$ \\
$\begin{array}{l}\text { E-Mail karger@karger.ch } \\
\text { www.karger.com }\end{array}$ & $\begin{array}{l}\text { Accessible online at: } \\
\text { www.karger.com/ced }\end{array}$
\end{tabular}

